\title{
DOES THE NUMBER OF JOINTS INVOLVED IN EXERCISE PROMOTE CHANGES IN ENERGY EXPENDITURE?
}

\author{
O NÚMERO DEARTICULAÇÕES ENVOLVIDAS NO EXERCICIO PROMOVE ALTERAÇÕES \\ DO GASTO CALÓRICO?
}

\section{¿EL NÚMERO DE ARTICULACIONES INVOLUCRADAS EN EL EJERCICIO PROMUEVE ALTERACIONES DEL GASTO CALÓRICO?}

\begin{abstract}
Gustavo Allegretti João 1,2 (iD) (Physical Education Professional) Daniel Rodriguez ${ }^{2}$ (ID) (Physical Education Professional) Roberta Luksevicius Rica ${ }^{2}$ (D) (Physical Education Professional) Nelson Cavas Júnior ${ }^{3}$ (D) (Physical Education Professional) Danilo Sales Bocalini ${ }^{4}$ (DD (Physical Education Professional) Aylton Figueira Júnior² ${ }^{2}$ D (Physical Education Professional)

1. Universidades Metropolitanas Unidas, Exercise Physiology Laboratory, São Paulo, SP, Brazil. 2. Universidade São Judas Tadeu (USJT), Physical Education Graduate Studies Program, São Paulo, SP, Brazil.

3. Instituto de Assistência Médica do Instituto de São Paulo, SP, Brazil. 4. Universidade Federal do Espírito Santo (UFES), Laboratory of Physiology and Experimental Biochemistry of the Center for Physical Education and Sports, ES, Brazil.
\end{abstract}

\section{Correspondence:}

Gustavo Allegretti João

Rua Taquari, 546, Mooca,

São Paulo, SP - 03166-000.

gustavoallegretti@hotmail.com

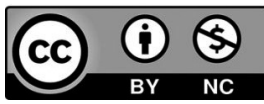

\begin{abstract}
Introduction: The benefits of strength training (ST) include not only strength improvement but also favorable body composition changes, which has led to a considerable increase in the indication of this training method in overweight and obese individuals, and has made the investigation of outcomes attributed to different manipulations of ST variables an important task. However, acute metabolic responses related to energy expenditure (EE) associated with the manipulation of exercises which, in turn, are associated with the number of joints involved in movement, are still inconclusive. Objective: To verify the influence of the number of joints involved in movement on EE with equalized volume in ST at different intensities. Methods: This training program was held on alternate days, with a 48-hour interval between each session, and with two randomized protocols, as follows: multi joint protocol with four common exercises for ST participants compared to the single joint protocol with four exercises. Each protocol was evaluated at three training intensities (90\%, $75 \%$ and $60 \%$ of 1-RM) according to the one-repetition maximum test. Results: Significant increases in EE were observed in the multi joint session as compared to the single joint session: $90 \%$ 1-RM multi joint $246.80 \pm 26.17 \mathrm{kcal}$ vs single joint $227.40 \pm 24.54 \mathrm{kcal}(\Delta-7.86,95 \% \mathrm{Cl} 7.33 ; 31.46 ; \mathrm{t} 3.44 ; \mathrm{p}<0.05)$; $75 \%$ 1-RM multi joint $124.13 \pm 25.40 \mathrm{kcal}$ vs single joint $111.80 \pm 22.78 \mathrm{kcal}(\Delta-9.93,95 \% \mathrm{Cl} 3.25 ; 21.41 ; \mathrm{t} 2.91$; $\mathrm{p}<0.05) ; 60 \%$ 1-RM multi joint $70.80 \pm 6.28 \mathrm{kcal}$ vs single joint $64.40 \pm 6.72 \mathrm{kcal}(\Delta-9.04,95 \% \mathrm{Cl} 3.95 ; 8.84$; t 5.60; $p<0.05$ ). Conclusion: Multi joint exercises may be a variable to consider when EE balance is the main target of the ST program. However, further studies are needed to supplement our findings. Level of evidence II; Diagnostic studies-Investigating a diagnostic test.
\end{abstract}

Keywords: Exercise; Energy expenditure; Muscle strength; Joints.

\section{RESUMO}

Introdução: Os beneficios do treinamento de força (TF) incluem não apenas aumento da força, mas também modificações favoráveis na composição corporal, o que levou ao aumento considerável da indicação dessa modalidade de treinamento em individuos com sobrepeso e obesidade e tornou importante a investigação dos desfechos atribuidos a diferentes manipulações das variáveis do TF. No entanto, as respostas metabólicas agudas relacionadas com o gasto calórico (GC) associado à manipulação dos exercícios que, por sua vez, são associados à quantidade de articulações envolvidas no movimento permanecem inconclusivas. Objetivo: Verificar a influência do número de articulações envolvidas no movimento sobre o GC com volume equalizado no TF em diferentes intensidades. Métodos: Esse treinamento foi realizado em dias alternados, com intervalo de 48 horas entre cada sessão com dois protocolos randomizados, a saber, protocolo multiarticular com quatro exercícios comuns para praticantes de TF em comparação com o protocolo monoarticular com quatro exercícios. Cada protocolo foi avaliado em três intensidades (90\%, 75\% e 60\% de 1-RM) do treinamento de acordo com o teste de uma repetição máxima (1-RM). Resultados: Foram observados incrementos significantes no GC na sessão multiarticular em comparação com a sessão monoarticular:

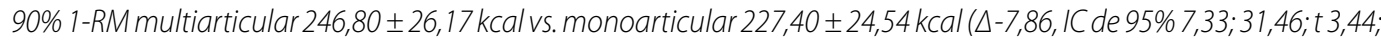
$p<0,05) ; 75 \%$ 1-RM multiarticular 124,13 $\pm 25,40$ kcal vs. monoarticular $111,80 \pm 22,78 \mathrm{kcal}(\Delta-9,93$, IC de $95 \% 3,25$; $21,41 ; t 2,91 ; p<0,05) ; 60 \%$ 1-RM multiarticular 70,80 $\pm 6,28 \mathrm{kcal}$ vs. monoarticular $64,40 \pm 6,72 \mathrm{kcal}$ ( $\Delta-9,04$, IC de $95 \%$ $3,95 ; 8,84 ; t 5,60 ; p<0,05)$. Conclusão: Os exercícios multiarticulares podem ser uma variável a considerar quando o equilíbrio do GC éo alvo principal do programa de TF. No entanto, mais estudos são necessários para complementar nossos achados. Nível de evidência ll; Estudos diagnósticos - Investigação de um exame para diagnóstico.

Descritores: Exercício; Gasto energético; Força muscular; Articulações.

\section{RESUMEN}

Introducción: Los beneficios del entrenamiento de fuerza (EF) incluyen no sólo aumento de la fuerza, sino también modificaciones favorables en la composición corporal, lo que llevó al aumento considerable de la indicación de esa modalidad de entrenamiento en individuos con sobrepeso y obesidad y se ha vuelto importante la investigación de las conclusiones atribuidas a diferentes manipulaciones de las variables del EF. Sin embargo, las respuestas metabólicas 
agudas relacionadas con el gasto calórico (GC) asociado a la manipulación de los ejercicios que, a su vez, son asociados a la cantidad de articulaciones involucradas en el movimiento permanecen no concluyentes. Objetivo: Verificar la influencia del número de articulaciones involucradas en el movimiento sobre el GC con volumen ecualizado en el EF en diferentes intensidades. Métodos: Este entrenamiento fue realizado en días alternados, con intervalo de 48 horas entre cada sesión con dos protocolos aleatorizados, a saber: protocolo multiarticular con cuatro ejercicios comunes para practicantes de EF en comparación con el protocolo monoarticular con cuatro ejercicios. Cada protocolo fue evaluado en tres intensidades (90\%, 75\% y 60\% de 1-RM) del entrenamiento de acuerdo con el test de una repetición máxima (1-RM). Resultados: Se observó un incremento significativo en el GC en la sesión multiarticular en comparación

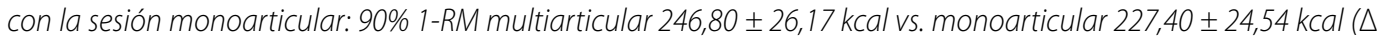
$-7,86$, IC de 95\% 7,33; 31,46; t 3,44; $p<0,05) ; 75 \%$ 1-RM multiarticular 124,13 $\pm 25,40$ kcal vs. monoarticular 111,80 \pm $22,78 \mathrm{kcal}(\Delta-9,93$, IC de 95\% 3,25; 21,41; t2,91, $p<0,05) ; 60 \%$ 1-RM multiarticular 70,80 $\pm 6,28 \mathrm{kcal}$ vs. monoarticular $64,40 \pm 6,72 \mathrm{kcal}(\triangle-9,04, \mathrm{IC}$ de $95 \%$ 3,95; 8,84; $t 5,60 ; p<0,05)$. Conclusión: Los ejercicios multiarticulares pueden ser una variable a considerar cuando el equilibrio del GC es el objetivo principal del programa de EF. Sin embargo, más estudios son necesarios para complementar nuestros hallazgos. Nivel de evidencia ll; Estudios diagnósticos Investigación de un examen para diagnóstico.

Descriptores: Ejercicio; Gasto de energía; Fuerza muscular; Articulaciones.

\section{INTRODUCTION}

The indication of strength training (ST) as a non-pharmacological strategy in the prevention and treatment of obesity is currently considered effective and efficient. ' Significant increases in oxygen consumption and consequently in energy expenditure (EE), depending on variables such as muscle mass, ${ }^{2}$ lifting tempo, ${ }^{3}$ number of sets, ${ }^{4}$ number of repetitions, ${ }^{5,6}$ training load, ${ }^{7}$ training volume, ${ }^{8}$ or recovery intervals, ${ }^{9-12}$ have been widely investigated and used on the basis of exercise prescription.

However, acute metabolic responses related to EE and the manipulation of exercises associated with the number of joints involved in movement have not been properly investigated. According to the American College of Sports Medicine, ${ }^{1}$ exercises for large muscle and/or multi joint volumes should be performed primarily in a training session, yet few studies $2,6,13,14$ have investigated these effects on EE.

Therefore, the literature is still lacking in studies investigating the relationship between EE in ST and the acute metabolic effects associated with the number of joints involved in exercises. Robergs et al. ${ }^{15}$ assessed EE during the execution of two multi joint exercises (bench press and squat) performed continuously over five minutes. The literature is still inconclusive about the influence of single joint and multi joint exercises on EE in ST sessions at different intensities. Thus, the objective of this study was to verify the influence of the number of joints involved on EE with equalized volume in ST at different intensities.

\section{MATERIALS AND METHODS}

\section{Experimental procedure}

To investigate EE in ST associated with the number of joints involved in the exercises, all the participants of this study performed two ST protocols on alternate days. The protocols had different intensities randomized by drawing lots, as follows: multi joint protocol (bench press, squat, front pulley and abdominal machine) and single joint protocol (pec deck, barbell curl, triceps pulley and only leg curl). Intensities corresponding to $90 \%, 75 \%$ and $60 \%$ of one repetition maximum (1-RM) were used.

For the prescribed intensity of $60 \%$ of 1-RM, the participants performed two sets (approximately 15 repetitions); at the intensity of 75\% of 1-RM they performed three sets (approximately 10 repetitions), and at the intensity of $90 \%$ of 1-RM the participants performed six sets (approximately 5 repetitions). All sets were performed to the point of momentary concentric muscle failure, operationally defined as the inability to perform another concentric repetition, while maintaining the proper form. All protocols had a 120-second recovery interval between sets and between exercises. The cadence of repetitions was maintained in a controlled manner (using a metronome), with concentric and eccentric actions lasting approximately 1.5 seconds, for a total repetition duration of approximately 3 seconds. The external load was adjusted for each exercise, as necessary, in successive sets to ensure that the subjects reached the point of failure in the target repetition interval.

Following approval by the institutional review board of Universidade São Judas Tadeu (No. 2.022.898/2016), 15 men with an average age of $22.9 \pm 2.61$ years, at least 12 months of experience in ST (weight training) and familiar with the proposed exercises participated voluntarily in the study. The following parameters were established as inclusion criteria: minimum experience of 24 months in weight training; minimum training frequencies of three times a week; submission of a medical certificate attesting to healthy clinical condition for participation. Subjects who met the following criteria were excluded from the study: smokers; those on diets both to reduce body mass and/or increase muscle mass; those with any metabolic disorders or taking drug products that affect energy expenditure (sympathomimetics, bronchodilators, antidepressants, amphetamines, illicit drugs); those who had sustained any muscle or tendon injury within the previous three months; those receiving treatment for an infectious or contagious disease; those taking (or those who had taken within the last six months) any type of ergogenic agent of hormonal origin for the purpose of increasing strength or hypertrophy; those who were absent at any stage of the assessments. All volunteers read and signed the Informed Consent Form.

\section{Preliminary assessments}

Body composition. Body mass (BM) was measured using a G-Tech ${ }^{\circledR}$ scale (Accumed Prod Med Hosp Ltda), with $0.100 \mathrm{~g}$ precision, with the subjects positioned on the Frankfurt plane, barefoot and wearing as little clothing as possible. Height $(\mathrm{H})$ was measured using a stadiometer (Sanny ${ }^{\circledR}$ with $0.1 \mathrm{~cm}$ precision). Body mass index (BMI) was obtained using the equation: $\mathrm{BM} /\left(\mathrm{H}^{2}\right)$. Circumference was measured using standard protocol according to previous publications. ${ }^{16,17}$ Fat percentage was measured by ultrasound (BodyMetrix ${ }^{\circledR}$ PRO System, Intelametrix, Livemore, California, USA - BodyViewTM software) with $2.5 \mathrm{MHz}$ wave frequency. ${ }^{16,17}$ The ultrasound probe was applied perpendicular to the skin for measurement. A water-soluble gel was used on the transducer to aid in acoustic coupling and to avoid excessive skin pressure. Subjects 
were instructed to fast for 3 hours before the assessments. The image was taken on the right side of the subjects' bodies and to further guarantee the accuracy of the assessments, at least three images were taken. The mean of the three assessments was used for statistical analysis (Table 1). Estimated food intake. To avoid possible dietary confusion in the results, subjects were advised to maintain their usual nutritional regimen and to avoid taking supplements during the study period. Dietary nutrient intake was assessed by 24-hour dietary recall on two non-consecutive business days and one weekend day. Subjects were instructed to record the following in detail: consumption time, types and quantity of meals and snacks consumed over 24 hours. The amount of food was recorded in culinary measures (spoons, cups and glasses) and transformed into grams. The energy intake estimate (macronutrients) was analyzed using NutWin software (USJT, São Paulo, Brazil), while estimated food intake was assessed during weeks of the intervention period.

Assessment of maximal muscle strength. Maximal dynamic strength was assessed through the 1-repetition maximum (1-RM) test, used in the multi joint (bench press, squat, front pulley and abdominal machine) and single joint (pec deck, barbell curl, triceps pulley and seated leg curl) exercises (Fitnessline equipment, GervaSport ${ }^{\circledR}$, Spain). The test protocol followed the recommendations prior to the previous publications. ${ }^{18}$ Subjects reported to the laboratory that they had abstained from any exercise other than activities of daily living for at least 72 hours before the test. In summary, participants warmed up for 5 minutes on a treadmill (Movement Technology, São Paulo, Brazil) at $60 \%$ of the maximum heart rate. During the first set, participants performed five repetitions

Table 1. Sample characterization

\begin{tabular}{c|c}
\hline Parameters & \\
\hline Age (years) & $22.90 \pm 2.61(0.11)$ \\
\hline Body mass $(\mathrm{kg})$ & $83.60 \pm 9.76(0.11)$ \\
\hline Height $(\mathrm{cm})$ & $183.07 \pm 5.60(0.03)$ \\
\hline Muscle mass $(\mathrm{kg})$ & $72.97 \pm 7.47(0.10)$ \\
\hline BMl $\left(\mathrm{kg} / \mathrm{cm}^{2}\right)$ & $24.89 \pm 2.15(0.08)$ \\
\hline$\sum$ Circumferences $(\mathrm{cm})$ & $431.39 \pm 21.87(0.05)$ \\
\hline$\Sigma$ Skin folds $(\mathrm{mm})$ & $37.75 \pm 11.27(0.29)$ \\
\hline Fat \% & $9.96 \pm 3.31(0.33)$ \\
\hline Fat mass $(\mathrm{kg})$ & $8.33 \pm 2.90(0.34)$ \\
\hline Muscle mass/Body mass $(\%)$ & $0.87 \pm 0.02(0.02)$ \\
\hline Resting metabolic rate & $2395.47 \pm 415.80(0.17)$ \\
\hline
\end{tabular}

Values expressed in mean \pm standard deviation (coefficient of variation). at an estimated 50\% 1-RM, followed by a set of three repetitions with a load corresponding to an estimated 60-80\% 1-RM, with a 180-second recovery interval between sets. After the warm-up sets, participants had five attempts to find their 1-RM load with 180-second intervals between each attempt. 1-RM was considered the maximum weight that could not be lifted more than once with the proper technique. It took no more than five attempts to achieve 1-RM with any subject. Verbal incentive was given throughout the tests. All test sessions were supervised by the research team to be considered valid (Table 2).

Assessment of energy expenditure. Before the data collection procedures, all participants underwent a two-week familiarization period during each exercise with the equipment (mask) for blood gas analysis (Fitmate ${ }^{\varpi}$ Cosmed) using sufficient load to perform a set of 20 repetitions. EE during the ST sessions was measured using a blood gas analyzer (COSMED ${ }^{\circledR}$, Fitmate, Rome, Italy) with flexible gas mask, according to previous publications. ${ }^{19-21}$ All participants were instructed not to drink coffee for 12 hours before the assessments, and not to exercise for 24 hours before the assessment. The blood gas analyzer was calibrated according to the manufacturer's specifications before each test. Following the calibration of the portable Fitmate unit, participants were equipped with a face mask held in place by a helmet. While the participants exhaled, an oxygen flowmeter and sampling line, coupled to the mask, collected data that included respiratory rate, air volume, and fractional oxygen concentration. The Fitmate metabolic unit calculated oxygen consumption $\left(\mathrm{VO}_{2}\right)$ internally, with each breath taken by the participants. Accordingly, $\mathrm{VO}_{2}$ was measured continuously (adding effort and recovery). For the final data presentation, the measured $\mathrm{O}^{2}$ was converted into units of energy (calories) using a conversion factor of 1 liter of $\mathrm{O}_{2}=5.05$ calories (kcal). ${ }^{11}$

For the EE analysis considering the anaerobic energy system, we used the model suggested by SCOTT et al. ${ }^{22}$ In short, lactate concentration was determined using a lactimeter model (Accusport Plus - Roche ${ }^{\circledR}$ ), following the recommendation of previous studies. ${ }^{28,29}$ Finger capillary blood samples were collected before the protocol (i.e., at rest), and immediately after the ST session. For anaerobic metabolic demand, it was measured by the difference between peak and baseline values $[\mathrm{La} \Delta]$, using the equivalent to $3 \mathrm{ml} \cdot \mathrm{kg}^{-1}$ of oxygen to each unit of accumulated lactate. ${ }^{11}$

\section{External measures of strength training volume and load}

Control of external training load. The most basic method for quantifying strength training is the repetition method for determining training

Table 2. 1-RM test and the \% of load used in each exercise.

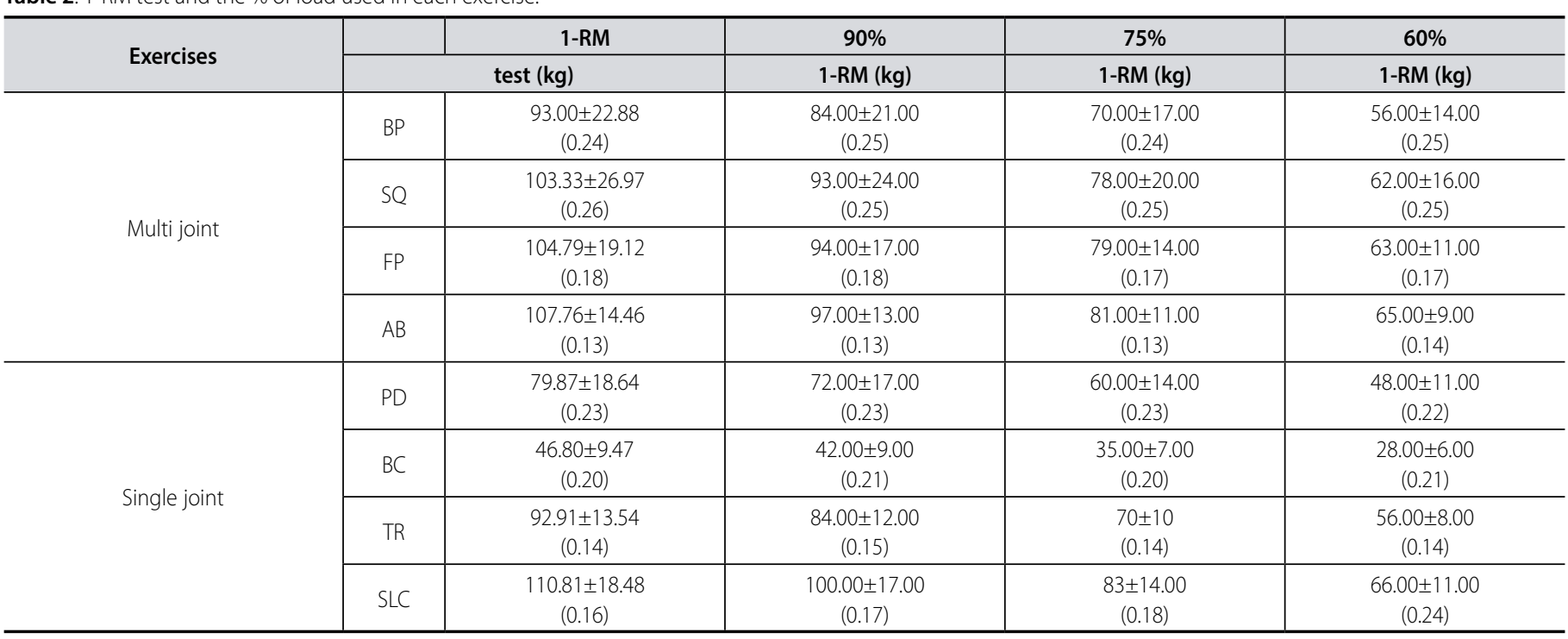


volume. The repetition method is simply the total number of repetitions performed in a specific exercise: a training session (Eq. 1) (Table 3).

Repetition volume $=$ no. of sets $\times$ no. of repetitions (Eq. 1)

The total weight lifted is an extension of the repetition method. It involves multiplying the number of repetitions performed for a given exercise by the absolute load lifted for those repetitions. In this manner, the training load (Table 3) for each different exercise performed in a training session can then be added up to calculate the total weight lifted and the training duration (Eq. 2).

\section{Training load $(T L)=$ no. of sets $\times$ no. of repetitions $x$ total weight lifted/session time (AU) (Eq. 2)}

\section{Statistical analysis}

The analysis of sample size was performed using GPower 3.1 software. ${ }^{23,24}$ Thus, assuming an estimation error of $a=0.05$, power $=80 \%$, with 3 measures (intensities) $x$ eight exercises, an $n$ of 15 was necessary to achieve the statistical power of $80.8 \%$. Therefore, 15 subjects were designated to undergo ST at different intensities. Repeated ANOVA measures were used to analyze energy expenditure values (8 exercises $x 3$ intensities), with Bonferroni's post-hoc test also employed when necessary. Assumptions of normality, homogeneity and sphericity were confirmed by Shapiro-Wilk, Levene and Mauchly tests, respectively. The paired Student's t test was used to analyze differences between the means of two sets of related scores, while the Wilcoxon test was applied for variables that did not satisfy the criteria for normality. ${ }^{25}$ Pearson's linear correlations were used to verify associations. The generalized eta squared $\left(\eta_{\mathrm{G}}{ }^{2}\right)$ was used as the effect size and interpreted according to Bakeman. ${ }^{26}$ General data for each exercise are presented as means, standard deviations and a 95\% confidence interval. Significance was set at 5\%. The data were processed using $\mathrm{R}$ software in version 1.0.44 for Macintosh.

\section{RESULTS}

There was no significant difference in the duration (minutes) of the multi joint vs. single joint sessions ( $90 \% 1-\mathrm{RM}=58.00 \pm 2.04$ vs. 56.00 $\pm 2.34 \mathrm{~min} ; 75 \% 1-\mathrm{RM}=30.70 \pm 1.63$ vs. $28.40 \pm 1.13 \mathrm{~min} ; 60 \% 1-\mathrm{RM}=$ $22.00 \pm 1.51$ vs. $18.99 \pm 2.01 \min ; p>0.05)$.
When comparing only the multi joint session, we observed significant differences in the volume of repetitions $\left(F_{(2.28)}=2.85 ; p=0.07\right.$; $\left.\eta_{\mathrm{G}}{ }^{2}=0.09\right)$; total weight lifted $\left(\mathrm{F}_{(2.28)}=553.67 ; \mathrm{p}=0.000 ; \eta_{\mathrm{G}}{ }^{2}=0.50\right)$; and training load $\left(F_{(2.28)}=89.03 ; p=0.000 ; \eta_{\mathrm{G}}{ }^{2}=0.54\right)$ between the ST intensities. Conversely, when we observed the single joint session alone, there was a significant difference only in the total weight lifted $\left(F_{(2.28)}=721.30 ; p=0.000 ; \eta_{\mathrm{G}}{ }^{2}=0.57\right)$ and training load $\left(F_{(2.28)}=76.44 ;\right.$ $\left.\mathrm{p}=0.000 ; \eta_{\mathrm{G}}{ }^{2}=0.59\right)$ between the different ST intensities.

There were no significant differences in the repetition volume when we compared the total volume between multi joint vs. single joint sessions. However, there were significant differences in the multi joint session when compared with the single joint session in the variables total weight lifted and training load (Table 3).

Significant differences in EE were observed between the different intensities in the multi joint $\left(F_{(2.28)}=321.59 ; \mathrm{p}=0.000 ; \eta_{\mathrm{G}}{ }^{2}=0.92\right)$; and single joint $\left(F_{(2.28)}=445.39 ; p=0.000 ; \eta_{\mathrm{G}}{ }^{2}=0.92\right)$ sessions. We also observed a significant increase in EE in the multi joint session when compared with the single joint session at all intensities (Table 4).

\section{DISCUSSION}

The objective of this study was to compare EE of the ST session associated with the number of joints involved in movement at different intensities in the ST. Therefore, three different ST intensities were performed (60, 75 and 90\% 1-RM), in sessions involving multi- and single joint exercises.

Our initial hypothesis of the study was confirmed; there was an increase in EE at high intensity and in multi joint sessions. The multi joint ST session showed an increase in EE when compared to the single joint session at all ST intensities. Our findings demonstrated an increase in EE between $\Delta=7.8$ and 9.9 in the multi joint session when compared to the single joint session.

When studying ST, there are countless possibilities for combinations between the variables of volume and intensity (number of sets, recovery

Table 4. Comparison of energy expenditure between the multi- and single joint sessions at different intensities.

\begin{tabular}{l|c|c|c|c|c|c}
\hline & Multi joint & Single joint & $\mathbf{\Delta}$ & $\mathbf{9 5 \%} \mathrm{Cl}$ & $\mathbf{t}$ & $\mathbf{P}=$ \\
\hline $90 \% 1-\mathrm{RM}$ & $246.80 \pm 26.17$ & $227.40 \pm 24.54$ & -7.86 & $7.33-31.46$ & 3.44 & 0.003 \\
\hline $75 \% 1-\mathrm{RM}$ & $124.13 \pm 25.40^{*}$ & $111.80 \pm 22.78^{*}$ & -9.93 & $3.25-21.41$ & 2.91 & 0.011 \\
\hline $60 \%$ 1-RM & $70.80 \pm 6.28^{*} \neq$ & $64.40 \pm 6.72^{*} \neq$ & -9.04 & $3.95-8.84$ & 5.60 & 0.000 \\
\hline
\end{tabular}

Table 3. Comparison of strength training variables between intensities and between multi joint vs. single joint sessions.

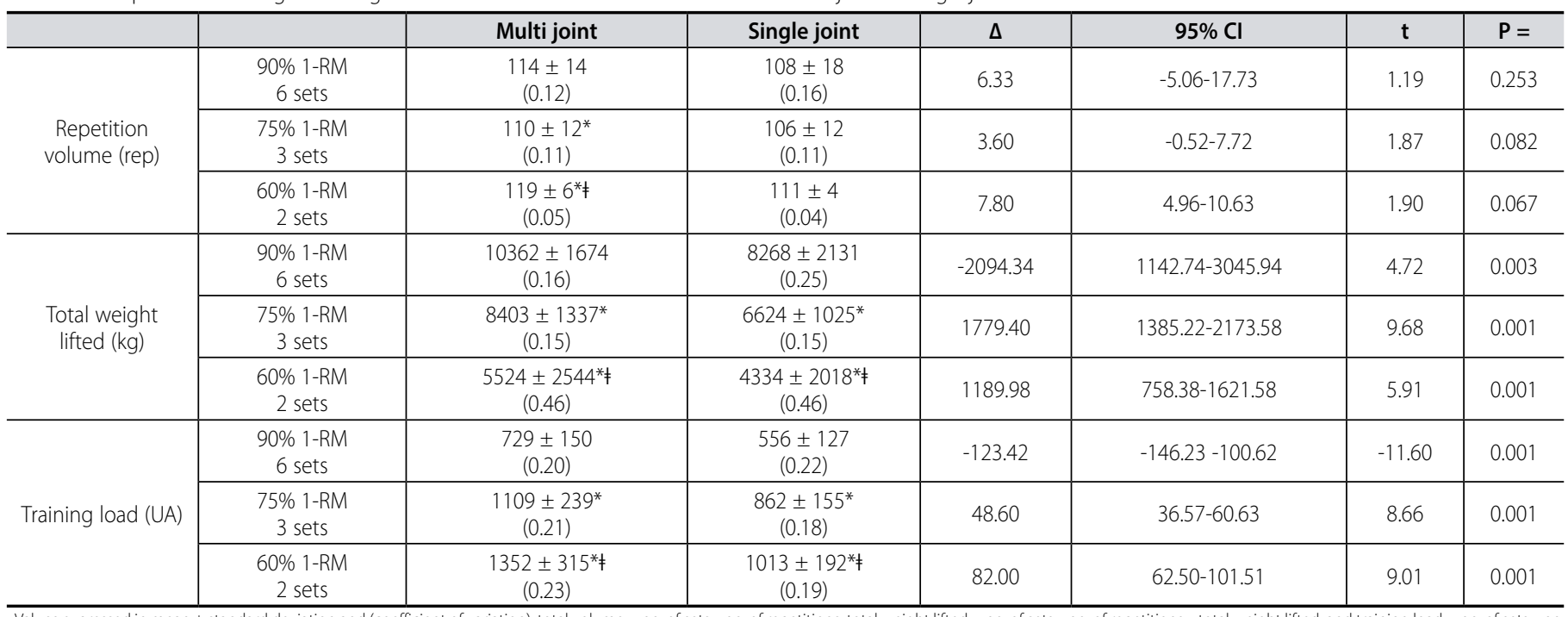


interval, number of repetitions, speed of execution, \% of poundage used in training and load, and training format) that can either increase or decrease EE. In this context, the order of exercises, ${ }^{2}$ the number of joints involved in movement, and the size of the muscle group can significantly increase EE. 2,14 Previous studies ${ }^{2,14,27}$ believe that some acute training variables have a greater positive or negative influence on $\mathrm{EE}$.

In this context, we chose to equalize the total number of repetitions (volume) of the training program, and to investigate the effect of intensity and the number of joints involved in movement (multi joint and single joint). Thus, the limitation of the study was the impossibility of equalizing the other variables. When ST is performed at high intensity (weight in $\mathrm{kg}$ lifted), it precludes a high number of repetitions, thereby entailing an increase in the number of sets and recovery intervals between sets. At the same time, the increase in the training session duration will result in a reduction of the training load.

Accordingly, in this particular study, when we observe ST variables such as total weight lifted, session duration and training load, with the exception of the training volume that was equalized at all intensities, EE at the intensity of $90 \%$ of 1-RM was significantly greater. However, there was an increase in the session duration and the total weight lifted. On the other hand, the training load, which is the combination of ST variables (volume and intensity), was significantly reduced.

To this end, Farinatti et al. ${ }^{14}$ investigated the order of strength exercises in EE. Two protocols were performed: sequence $A$ from multi joint to single joint and sequence $B$ from single joint to multi joint in the following exercises: bench press (multi joint), shoulder development (multi joint), and triceps extension (single joint). The main conclusions indicated that the acute performance was significantly affected by the exercise order, but, in general, EE was not affected by the exercise order. Subsequently, Farinatti et al. ${ }^{2}$ observed the influence of the muscle group size on EE. The protocol was randomized in five sets, 10 repetitions, with a load corresponding to 15 repetitions maximum, in two leg-press (LP) and bench press (BP) exercises. The results showed that EE was significantly influenced by the muscle mass involved in the exercise (88-91 kcal in the $\mathrm{LP}$ and $50-54 \mathrm{kcal}$ in the BP exercises). Ratamess et al. ${ }^{27}$ investigated the relationship between maximal oxygen consumption in ST and the acute metabolic effects of the exercise sequence. Accordingly, two protocols were randomly performed, squat first followed by bench press, and/or bench press first followed by squat. Both protocols were composed of five sets of each exercise with 75\% of 1-RM, 10 repetitions. The results showed a tendency towards an increase in oxygen consumption when the squat exercise was performed first, i.e., multi joint and large muscle groups.

Therefore, there are countless possibilities for combinations between the variables of volume and intensity that can increase or reduce EE. In this context, the order of exercises ${ }^{2}$ and the number of joints involved in movement as well as muscle group size can significantly increase EE. 2,14
Studies ${ }^{3,28-30}$ indicate that training volume has been one of the main determinants of EE during ST sessions. Thus, considering the studies available in the literature, it is possible to consider a significant increase in EE in protocols with high volume when compared to low training volume with other acute training variables, such as recovery intervals, speed of movement or training intensity. $3,28-30$

Thornton et al. ${ }^{8}$ demonstrated a similar EE response when the repetition volume was equalized. Our results do not support these findings, demonstrating that the total repetition volume did not influence EE. In this particular study, the total repetition volume of the training program was similar between the multi joint sessions and the single joint training session. In addition, in this study, total EE was significantly higher when performed at an intensity of 90\% 1-RM, demonstrating that intensities (total weight lifted) can be important variables in the increase of EE in ST, not corroborating the aforementioned studies.

Moreover, studies ${ }^{3,30}$ have shown a significant increase in EE in high intensity protocols, compared with low intensity in ST. Hunter et al. ${ }^{3}$ compared EE with intensity of $25 \%$ of 1-RM and intensity of approximately $70 \%$ of $1-\mathrm{RM}$ in seven trained young men. Thus, the total EE was 45\% higher with high intensity $(155 \pm 28 \mathrm{kcal})$ when compared to low intensity $(107 \pm 20 \mathrm{kcal})$. Reis et al. ${ }^{30}$ estimated EE at various intensities, yet the ST sessions are held in four constant 5-minute sets at the following intensities: $12 \%, 16 \%, 20 \%$ and $24 \%$ of $1-\mathrm{RM}$, hindering a comparison between studies.

Therefore, the proposal to elucidate EE for different ST protocols, i.e., by assigning values to the variables of intensity, volume, pause for recovery between sets and exercises, and the number of exercises, would result in changes in EE associated with the session. The study analyzed EE for three protocols that were different but shared the same number of exercises, recovery interval and total repetition volume (repetitions $x$ sets), arriving at different EE values for each protocol as presented (Table 4).

\section{CONCLUSIONS}

The possible breakdowns of the values will depend on the strategy adopted in the prescription of ST. For instance, if the subject has absolute EE as a goal, the most appropriate protocol would be high intensity $90 \%$ 1 -RM with exercises that involve more joints in movement (multi joint exercises). In view of the above, ST represents a plausible strategy for maintaining body weight and even for reducing it, where each protocol presented has an advantage and should be used according to the needs and objectives of the training participant.

All authors declare no potential conflict of interest related to this article

AUTHORS' CONTRIBUTIONS: Each author made significant individual contributions to this manuscript. GAJ and DSB were the main contributors in the drafting of the manuscript. DR, RLR and NC followed the protocols and collected the data. AFJ and NC evaluated the data from the statistical analysis. DR, performed the bibliographic search, reviewed the manuscript and contributed to the study's intellectual concept.

\section{REFERENCES}

1. Garber CE, Blissmer B, Deschenes MR, Franklin BA, Lamonte MJ, Lee IM, et al. American College of Sports Medicine Position Stand. Quantity and quality of exercise for developing and maintaining cardiorespiratory, musculoskeletal, and neuromotor fitness in apparently healthy adults: Guidance for prescribing exercise. Med Sci Sports Exerc. 2011;43(7):1334-59.

2. Farinatti PT, Castinheiras Neto AG. The effect of between-set rest intervals on the oxygen uptake during and after resistance exercise sessions performed with large-and small-muscle mass. J Strength Cond Res. 2011;25(11):3181-90.

3. Hunter GR, Seelhorst D, Snyder S. Comparison of metabolic and heart rate responses to super slow vs. Traditional resistance training. J Strength Cond Res. 2003;17(1):76-81.

4. Haddock BL, Wilkin LD. Resistance training volume and post exercise energy expenditure. Int J Sports Med. 2006;27(2):143-8.
5. Ratamess NA, Falvo MJ, Mangine GT, Hoffman JR, Faigenbaum AD, Kang J. The effect of rest interval length on metabolic responses to the bench press exercise. Eur J Appl Physiol. 2007;100(1):1-17.

6. Ratamess NA, Rosenberg JG, Kang J, Sundberg S, Izer KA, Levowsky J, et al. Acute oxygen uptake and resistance exercise performance using different rest interval lengths: the influence of maximal aerobic capacity and exercise sequence. J Strength Cond Res. 2014;28(7):1875-88.

7. BonganhaV, Conceição MS, Chacon-Mikahil MP, Madruga VA. Resposta da taxa metabólica de repouso após 16 semanas de treinamento com pesos em mulheres na pós-menopausa. Rev Bras Med Esporte. 2011;17(5):350-3.

8. Thornton MK, Potteiger JA. Effects of resistance exercise bouts of different intensities but equal work on EPOC. Med Sci Sports Exerc. 2002;34(4):715-22.

9. Almeida AP, Coertjens M, Cadore EL, Geremia JM, Silva AE, Kruel LF. Consumo de oxigênio de recuperação em resposta a duas sessöes de treinamento de força com diferentes intensidades. Rev Bras Med Esporte. 2011;17(2):132-6. 
10. Buitrago S, Wirtz N, Yue Z, Kleinöder H, Mester J. Mechanical load and physiological responses of four different resistance training methods in bench press exercise. J Strength Cond Res. 2013;27(4):1091-100.

11. Scott CB. Contribution of blood lactate to the energy expenditure of weight training. J Strength Cond Res. 2006;20(2):404-11.

12. Børsheim E, Bahr R. Effect of exercise intensity, duration and mode on post-exercise oxygen consumption. Sports Med. 2003;33(14):1037-60.

13. Ratamess NA, Falvo MJ, Mangine GT, Hoffman JR, Faigenbaum AD, Kang J. The effect of rest interval length on metabolic responses to the bench press exercise. Eur J Appl Physiol. 2007;100(1):1-17.

14. Farinatti PT, Simão R, Monteiro WD, Fleck SJ. Influence of exercise order on oxygen uptake during strength training in young women. J Strength Cond Res. 2009;23(3):1037-44.

15. Robergs RA, GordonT, Reynolds J, WalkerTB. Energy expenditure during bench press and squat exercises. J Strength Cond Res. 2007;21(1):123-30.

16. Utter AC, Hager ME. Evaluation of ultrasound in assessing body composition of high school wrestlers. Med Sci Sports Exerc. 2008;40(5):943-9.

17. Johnson KE, Naccarato IA, Corder MA, Repovich WE. Validation of Three Body Composition Techniques with a Comparison of Ultrasound Abdominal Fat Depths against an Octopolar Bioelectrical Impedance Device. Int J Exerc Sci. 2012;5(3):205-13.

18. Kraemer WJ, Fry A. Strength testing: development and evaluation of methodology. In: Physiological assessment of human fitness. Champaign $\mathrm{IH}$, editor. 1995. 115-38 p.

19. Lee JM, Bassett Jr DR, Thompson DL, Fitzhugh EC. Validation of the cosmed fitmate for prediction of maximal oxygen consumption. J Strength Cond Res. 2011;25(9):2573-9.

20. Nieman DC, Lasasso H, Austin MD, Pearce S, McInnis T, Unick J. Validation of cosmed's fitmate in measuring exercise metabolism. Res Sport Med. 2007;15(1):67-75.
21.Yavelberg L, Zaharieva D, Cinar A, Riddell MC, Jamnik V. A Pilot study validating select research-grade and consumer-based wearables throughout a range of dynamic exercise intensities in persons with and without type 1 diabetes: a novel approach. J Diabetes Sci Technol. 2018;12(3):569-76

22. Scott CB, Leighton BH, Ahearn KJ, McManus JJ. Aerobic, anaerobic, and excess postexercise oxygen consumption energy expenditure of muscular endurance and strength: 1-set of bench press to muscular fatigue. J Strength Cond Res. 2011;25(4):903-8.

23. Eng J. Sample Size Estimation: How Many Individuals Should Be Studied? Radiology. 2003;227(2):309-13. 24. Faul F, Erdfelder E, Lang AG, Buchner A. G*Power 3 : A flexible statistical power analysis program for the social, behavioral, and biomedical sciences. 2007;39(2):175-91.

25. Razali NM, Wah YB. Power comparisons of shapiro-wilk, kolmogorov-smirnov, lilliefors and andersondarling tests. J Stat Model Analytics. 2011;2(1):21-33.

26. Bakeman R. Recommend effect size statistics for repeated measure designs. Behav Res Methods. 2005;37(3):379-84.

27. Ratamess NA, Rosenberg JG, Kang J, Sundberg S, Izer KA, Levowsky J, et al. Acute oxygen uptake and resistance exercise performance using different rest interval lengths: The influence of maximal aerobic capacity and exercise sequence. J Strength Cond Res. 2014;28(7):1875-88.

28. Hunter GR, Byrne NM, Sirikul B, Fernández JR, Zuckerman PA, Darnell BE, et al. Resistance training conserves fat-free mass and resting energy expenditure following weight loss. Obesity (Silver Spring) 2008;16(5):1045-51

29. Heden T, Lox C, Rose P, Reid S, Kirk EP. One-set resistance training elevates energy expenditure for $72 \mathrm{~h}$ similar to three sets. Eur J Appl Physiol. 2011;111(3):477-84.

30. Reis VM, Garrido ND, Vianna J, Sousa AC, Alves JV, Marques MC. Energy cost of isolated resistance exercises across low- to high-intensities. PLoS One. 2017;12(7):e0181311. 